\title{
ANTECEDENTES $\Upsilon$ CAUSAS DEL PROCESO $\Upsilon$ PENSAMIENTO INDEPENDENTISTA EN LAS COLONIAS HISPANO LUSAS Y SU VÍNCULO CON LA IDEA DE JUSTICIA
}

\author{
ANTECEDENTES E CAUSAS DO PROCESSO E DO PENSAMENTO INDEPENDENTE \\ NAS COLÔNIAS LUSO-HISPÂNICAS E SEU VÍNCULO COM A IDEIA DE JUSTIÇA
}

\section{ANTECEDENTS AND CAUSES OF THE PROCESS OF THE INDEPENDENCE THINKING IN LUSO-HISPANIC COLONIES AND HOW THEY ARE RELATED TO THE IDEA OF JUSTICE}

\section{Edgardo Romero Fernández ${ }^{1}$}

Licença CC BY:

Artigo distribuído sob os termos Creative Commons, permite uso e distribuição irrestrita em qualquer meio desde que o autor credite a fonte original.

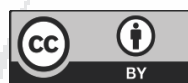

Resumen: Las acciones de dominación por parte de las distintas metrópolis, que colonizaron el territorio que se conocerá posteriormente como América Latina engendraron desde su inicio una acción y un sentimiento anti injerencista, que responderá a lo que será y es conocido en la literatura científica como justicia. Las acciones encaminadas a otorgar y/o restablecer la justicia en los territorios de los pueblos originarios de América a su vez generaron una acción y pensamiento independentista en la región, por lo que se puede afirmar que la idea de justicia en el sentido occidental que posee este término está fuertemente ligada al proceso de colonización y a su contrario: el pensamiento anticolonial y la acción independentista en América latina.

Palabras Clave: justicia, América Latina, colonización de América, independencia latinoamericana

Resumo: As ações de dominação por parte dos diferentes países que colonizaram o território que posteriormente passou a ser conhecido como América Latina levaram, desde o seu início, a uma ação e a um sentimento antiintervencionista, o qual responderá ao que veio a ser e é conhecido na literatura científica como justiça. As ações com o intuito de outorgar e/ou reestabelecer a justiça nos territórios dos povos originários da América geraram, por sua vez, uma ação e um pensamento de pró independência na região, o que pode levar a afirmar que a ideia de justiça no sentido ocidental que este termo possui está fortemente ligada ao processo de colonização e que, o contrário, é o pensamento anticolonialista e a ação pró independência da América Latina.

$1 \quad$ Doctor en Filosofía con Pos doctorado en Pensamiento político latinoamericano en la Universidad Autónoma de Madrid, España; Profesor Titular de Teoría política de la Universidad Central "Marta Abreu" de las Villas, Cuba. 


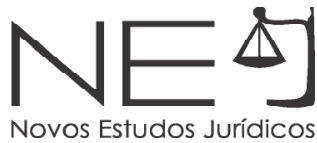

Palavras - Chave: justiça, América Latina, colonização de América, independência latinoamericana.

Abstract: Actions of domination by the different countries that colonized the territory that later came to be known as Latin America carried, from the very beginning, an anti-interventionist action and sentiment, which would respond to what came to be known in the scientific literature as justice. The actions aimed at graining and/or reestablishing justice in the territories of native peoples of America generated, in turn, an action of pro-independence thinking in the region, which could lead us to affirm that the idea of justice in the western sense, which this term carries, is strongly linked to the process of colonization, and that the opposite is the anti-colonialist thinking and pro-independence action of Latin America.

Keywords: justice, Latin America, colonization of America, Latin-American Independence

\section{ANTECEDENTES Y CAUSAS DEL PROCESO Y PENSAMIENTO INDEPENDENTISTA EN LAS COLONIAS HISPANO LUSAS}

Las Reformas Borbónicas, en particular las Legislaciones Comerciales, dictadas entre 1778 y 1782, en sentido general repercutieron en prejuicio del comercio libre con otros países, incluyendo a la propia España, pero en alguna medida permitieron una mayor apertura al mercado mundial, o al menos al comercio con potencias y zonas importantes en este rubro. Gracias a dichas reformas, se reactivó la minería en Nueva España, cobró impulso la campaña colonizadora en los territorios marginales (visible en Las Antillas, el litoral venezolano y Río La Plata, aumentó la economía de plantaciones en el Caribe (apareciendo los cultivos tropicales de la caña de azúcar y el cacao en las Antillas Menores), y se desarrolla la economía de exportación en regiones costeras, así como en algunas áreas interiores, tales como la Pampa argentina.

En consecuencia, a fines del XVIII se percibe un incremento de la producción agrícola y ganadera en varias zonas, sobrepasando este renglón a la minería. Como contrapartida, y a la vez por estas mismas razones, las medidas borbónicas contribuyeron a modificar la estructura clasista de la sociedad colonial, estableciéndose un mayor equilibrio entre la burguesía comercial, el clero y los funcionarios, por una parte; y la rica aristocracia criolla, por la otra. 
Aparecen también grupos emergentes vinculados al comercio exterior y el capital en varias regiones como La Habana, Veracruz, Caracas y Buenos Aires. ${ }^{2}$ La existencia de un sector de plantadores y propietarios territoriales y comerciantes criollos acomodados en el seno de la oligarquía hispanoamericana, (no vinculados a los mayorazgos en el proceso de aburguesamiento) conjuntamente con el auge de las pequeñas burguesías locales, (intelectuales y profesionales, sobre todo) trae consigo un aumento de las contradicciones de clase. De ahí el incremento de las peticiones a favor de una mayor liberalización del comercio para el acceso directo al vínculo comercial ultramarino. Dichas peticiones, de marcado sesgo reformista, eran expresión de formas de lucha por la justicia social para esos sectores que, aunque privilegiados con respecto al resto de la sociedad, no se sentían satisfechos con el orden de cosas colonial, pues les limitaba su forma de vida. Lo cual constituye una base objetiva para que se genere un pensamiento y visión del mundo contrario al pensamiento y forma de vida dilapidadores de las Corte metropolitana 3 .

Las clases trabajadoras, por su parte, se veían cada vez más asfixiadas, por lo que se potenciaron los amplios movimientos de rebeldía enunciados, que, si bien se sustentan básicamente en razones económicas y sin una proyección política conscientemente definida, alcanzan grandes dimensiones y evidencian la búsqueda de vías alternativas a la explotación de los gobiernos coloniales. Esas vías alternativas, que aparecen en función de la sobrevivencia, van llenando de un nuevo contenido la idea de justicia social que manejan los grupos y clases subalternas. Dichas vías alternativas en busca de la justicia, a su vez, tienen causas objetivas y subjetivas.

2 Según Manfred Kossok, por las razones económicas, es la aristocracia la clase predominante, lo cual explica que no se profundicen luego las Revoluciones Latinoamericanas. Al respecto, manifiesta el autor: "Del antagonismo (...) entre los sectores artesano-manufacturero y minero-agropecuario se derivan dos importantes conclusiones sociales; mientras se volvían más desfavorables los prerrequisitos económicos para la consolidación de una burguesía autócrata (...) se desarrollaba al mismo tiempo un proceso en sentido opuesto, el fortalecimiento de la burocracia latifundista criolla. Se presentan como clase dominante del futuro, fuerzas político-sociales que permanecen en esencia vinculadas a defender el status quo, al trasponer los elementos básicos del feudalismo colonial al período de la independencia." Para profundizar más al respecto, ver Manfred Kossok: La Revolución en la Historia de América Latina. La Habana, Ciencias Sociales, 1989, pp. 127-128.

3 Se plantea aquí una contradicción entre la ética del ocio y el derroche, propia del señorío feudal, y la ética del trabajo o el espíritu del capitalismo, tal y como lo plantea Max Weber. Al respecto, ver: Max Weber: "La Ética Protestante y el Espíritu del Capitalismo". Ediciones Península, Barcelona, 1994. 
Las contradicciones con la metrópoli habían hecho crisis también en la esfera de la circulación monetaria. ${ }^{4}$ Los grupos emergentes acentúan sus pugnas tanto con la oligarquía criolla como con los funcionarios españoles, que monopolizaban el aparato estatal con sus rentas fiscales, el control del comercio y la administración de las tierras baldías o relegadas. La tendencia de los terratenientes ante ello fue adoptar posiciones moderadas y aliarse al alto clero y otros sectores del aparato colonial. Así lo hicieron también los latifundistas y comerciantes criollos en aquellos sitios donde dichos movimientos eran incontenibles (México, Perú, Guatemala, Brasil, Cuba, etc.). Sin embargo, los criollos tenían aspiraciones al gobierno propio y a terminar con los prejuicios que frenaban su enriquecimiento económico.

Las ideas de la ilustración potenciadas con las revoluciones en Norteamérica y Francia ya citadas contribuyeron de forma vital a formar las ideas independentistas en los criollos ilustrados hacia fines del siglo XVIII y principios de XIX, desde ya se observan agudizadas en extremo las contradicciones básicas desde el punto de vista regional, económico, administrativo, político, cultural y -más que nada- socio-clasista. Esto se intensifica con la invasión napoleónica a España, que hace caer a dicha monarquía ante el caudillo francés en 1808. De esta manera, surgen organizaciones revolucionarias en las logias secretas. La prensa comienza a ser un instrumento importante para las ideas progresistas, y sobresalen figuras opuestas a la dominación extranjera en el plano intelectual.

Los terratenientes, en buena medida ya permeados de ideas liberales, organizaron juntas de gobierno análogas a la estructura gubernativa española con la intención de sustituirlas ante su pérdida de fuerzas. Sin embargo, lo que muchos han llamado el movimiento juntista criollo no era homogéneo, apareciendo visiblemente dos tendencias: una leal a Fernando VII (que aceptaba en no pocos casos las juntas de gobierno solo como una medida temporal hasta lograr la expulsión de los franceses), y otra más radical, que, dirigida por los latifundistas, comerciantes e intelectuales, busca el control del poder

4 Para autores de la talla de Javier Ocampo López, la crisis en la metrópoli y la situación de América guardan una relación más estrecha de lo que habitualmente se concibe: "La coyuntura de la revolución de independencia española se proyectó en las colonias americanas, pues se formó un conjunto en crisis, en el cual la matriz o metrópoli en plena decadencia y caída de la monarquía, presionó la crisis de todo el Imperio español." Ver en: Javier Ocampo: El Proceso Ideológico de la Emancipación en Colombia. Planeta, Bogotá, 1999, p. 32. 
Novos Estudos Jurídicos

político para implantar medidas (al menos en principio) de corte liberal, en especial en la esfera comercial.

Desde los protagonistas de aquellos acontecimientos y sus contemporáneos hasta la actualidad se han intentado resumir las causas de la independencia, disponiéndose hoy de una extensa relación de motivos originarios desde las más variadas aristas y grados clasificatorios disímiles. Pero no siempre se llega a analizar el nivel de generalidad de cada una de estas causas para situarlas en la perspectiva adecuada, comprendiendo su importancia con respecto a las demás y -quizás lo más importante- atendiendo a la diversidad regional. Así, por ejemplo, cuando se atribuye el deseo de independencia a la corrupción administrativa y la inmoralidad burocrática por parte de las autoridades españolas, o a la relajación de las costumbres del clero, pueden aparecer notables diferencias. Otras posibles causas aducidas reiteradamente, como la crueldad y el despotismo conque eran tratados los indígenas y las restricciones culturales impuestas por las autoridades españolas, están en abierta contradicción (aunque igualmente ocurran) con la realidad en ciertos territorios en cuanto a las dimensiones de incidencia en el descontento masivo, teniendo en cuenta las características específicas de los grupos socio-clasistas concretos, los intereses económicos, la perspectiva del papel de la metrópoli como causante de sus penalidades, etc. En los virreinatos del Perú y Nueva Granada, y hasta cierto punto en el de Nueva España, muchos indígenas militaron en el bando realista, lo que dio a los enfrentamientos en esos territorios un carácter de guerra civil para no pocos observadores.

La existencia de universidades en muchas de las más importantes ciudades hispanoamericanas, así como la formación cultural en ellas de los propios caudillos independentistas son otros tantos argumentos en contra de la generalización de estas razones mencionadas, necesitadas de precisiones, como sucede también con la rivalidad motivada por el establecimiento de gabelas y trabas que dificultaban el desarrollo de la economía para sí en las colonias y frenaba el crecimiento de su capacidad productiva.

La legislación española no diferenciaba entre los españoles peninsulares y criollos, por lo que el problema se planteaba, igual que en España, entre los 
naturales de una región, provincia o reino que aspiraban a ocupar los puestos de la administración en su tierra, y los que provenían de otras zonas, ocupaban los cargos y desplazaban a los naturales (generalmente por residir en las cortes o estar representados en ellas). En otros ámbitos, no dejaría de ser otro elemento impulsor la concepción patrimonial del Estado, pues Las Indias estaban vinculadas a España a través de la persona del monarca, y las abdicaciones forzadas Carlos IV y Fernando VII rompieron en 1808 la legitimidad establecida, e interrumpieron los vínculos existentes entre la Corona y los territorios hispanoamericanos, que se vieron rápidamente en la necesidad de atender a su propio gobierno. Mientras, externamente, influiría la difusión de las doctrinas alternativas que, basándose en los ideales europeos (de vieja y de nueva factura) sostenían que la soberanía revierte al pueblo cuando falta la figura del rey. Esta doctrina de la soberanía popular, vigente en España, influyó en los independentistas tanto como las emanadas del pensamiento ilustrado -consabidamente influyente y decisivo-del siglo XVIII. La labor que por años desempeñaron los jesuitas en Latinoamérica es otro elemento a tomar en cuenta, pues sus críticas contra la actuación española en América después de su expulsión de España (1767), plasmadas en abundantes publicaciones, tuvieron gran importancia en la generación de un clima de oposición al dominio español entre la burguesía criolla.

Tanto los ideales de la ilustración inglesa y francesa como los preconizados por la independencia norteamericana, unidos a los postulados del liberalismo influyeron notablemente en muchos dirigentes independentistas y en personajes destacados de la cultura como Andrés Bello, José De La Luz y Caballero, etc; en algunos casos de forma distorsionada y otras con cierto carácter sistémico, mayor o menor, lo cual sería decisivo en el ideal independentista e integracionista posterior. Tales son los casos de Miranda, San Martín, Bolívar, Moreno, Alvear, O’Higgins, Carrera Verdugo, Pío de Montúfar, Rocafuerte y muchos otros, que con frecuencia se encontraron en Europa o mantuvieron vínculos con sus centros políticos y los de Estados Unidos. Ello les permitió equiparse ideológicamente, pero también la posibilidad de contar con apoyos externos y las necesarias fuentes de financiación para sus proyectos, lo cual marcaría igualmente su percepción del proceso emancipador y de las bases internacionales sobre las cuales erigir a los futuros Estados emancipados. 
Aquellas contradicciones gestadas por el poder colonial arraigado durante más de tres siglos continuarían y aún se complejizarían notablemente durante el Proceso Emancipador, incluyendo el mencionado conflicto del desarrollo regional y sus aportes al objetivo liberador en correspondencia con las potencialidades físico-geográficas de las diferentes zonas enfrascadas en el conflicto. De esta forma, el modo en que España, concretamente, defiende con mayores o menores recursos militares una u otra región se corresponde con la utilidad actual de dichos espacios en la concepción compensatoria y sostenedora de su economía. Las faltas de vínculo interregional, tanto en lo económico como en lo específicamente comercial, se expresarán ahora en descoordinaciones, falta de unidad y concretamente regionalismos acentuados; todos ellos de inmediata urgencia para consolidar los factores que harían posible la Independencia, pero que en no escasa medida, o bien se lograrían solo de manera temporal, a partir de intereses comunes, o bien no cuajarían en medida suficiente como para que sirvieran de apoyo viable a los nuevos Estados libres que surgirían posteriormente. La carencia de vinculación entre importantes centros urbanos, particularmente, donde se concentran importantes círculos intelectuales y militares para conducir el proceso, lo afectaría sobremanera; como también lo haría la falta de una industrialización que soportara materialmente la guerra y la radicalización uniforme u homogénea, con similares paradigmas económicos y políticos, del pensamiento de las élites que dirigen la Emancipación, en ocasiones con una postura reconocidamente conservadora. ${ }^{5}$

La mirada hacia círculos de poder externos como posible punto de apoyo para las bases del nuevo estatus, ajenos a España y Portugal, no es poco recurrente en muchos de los líderes criollos, algunos de los cuales postulan a viva voz proyectos que trascienden el simple ámbito de las relaciones comerciales y diplomáticas en torno a potencias como Inglaterra y Estados Unidos (siendo

$5 \quad$ A decir de José Luis y José Antonio Romero sobre la conducta de estos sectores conservadores posteriormente a la Independencia, "formaba parte de este núcleo original del pensamiento conservador una concepción autoritaria de la vida social y política, heredada de la estructura virreinal, sostenido por el pensamiento político de la monarquía española y de Iglesia Católica. La república convirtió a los antiguos poseedores de tierra y minas (...) en una oligarquía política de cuyas tendencias autoritarias se canalizaron a ser apoyo de un poder fuerte, aunque fuera centralizado y unipersonal, con la condición de que representará una garantía del orden socioeconómico tradicional." Ver: José Luis y José Antonio Romero (Ed.): Pensamiento Conservador en América. Avacucho. Caracas, 1971, p. XVII. 
típico, en el primer caso, la postura de muchos elementos criollos de Brasil, cuya Historia colonial cuenta con un antecedente obviamente fuerte de dependencia inglesa con características bien llamativas).

Por otra parte, la percepción de la necesidad liberadora y el sueño del futuro desarrollo no trascenderán los criterios fronterizos establecidos por el sistema administrativo colonial. Esto se debe a las mismas razones por las que las respectivas Coronas mantienen esa visión administrativa: la percepción de potencialidades geofísicas ajustadas al régimen de extirpación de riquezas vigente y no a las potencialidades regionales vistas a largo plazo. De este modo, las esperanzas de desarrollo autónomo que preconicen los líderes independentistas, y aún la distribución territorial con la cual emprendan sus respectivas campañas militares, responden a una idea no tan lejana de la de las metrópolis sobre las referidas potencialidades. ${ }^{6}$

Políticamente, la toma del poder significa una necesidad de primer orden por parte de todos los sectores locales que se oponen a España, pero no todos requieren conscientemente su ejercicio directo, pues subvaloran sus capacidades de clase, estando dispuestos a entregar sus destinos al sector elitista criollo que también en el proceso liberador concreto ejerce el liderazgo.7 Por ello, en todos

$6 \quad$ El objetivo liberador de la mayor parte de los próceres, con pocas excepciones entre las que se puede señalar a Bolívar y San Martín, si bien podía declararse en torno a conceptos y espacios territoriales más amplios, en la práctica se circunscribía a una concepción estratégica centrada en la región que no rompía con los criterios fronterizos de la estructura colonial. De este modo, Hidalgo y Morelos no se extendieron a la parte del virreinato novohispano donde existían pequeñas administraciones autónomas (actuales países de Centroamérica), cuyos protagonistas, en cambio, concibieron la Independencia solo a partir de aquel influjo, pero bajo su propia égida política y militar, para luego enfrascarse, más o menos convencidos, en el proyecto unificador de Morazán. Panamá fue comprendido dentro de la estrategia Venezolana y Neogranadina de Bolívar y compañía, y no dentro del contexto centroamericano, tal y como colonialmente funcionaba su territorio. El Alto Perú contó con la incursión de varios ejércitos libertadores, pero también sin romper con su criterio fronterizo colonial. Chile, antigua Capitanía Liberal, fue liberada como región también distinguiblemente. Igualmente se distingue el Perú de la estrategia bolivariana. Puede observarse muy distintivamente este fenómeno es en el antiguo Virreinato de Río La Plata, cuyas Provincias Unidas no lo eran tanto de forma novedosa a la hora en que consumaron la Independencia para nuevos Estados. Conocidas son las marcadas diferencias entre los territorios de las actuales Uruguay, Argentina y Paraguay desde la época colonial. No obstante, el ejemplo más claro está en el sur brasileño, con el hecho de que, ni siquiera en medio de la diferenciación y contradicción durante y después de la gesta, sus fronteras con dichos territorios variaron de forma prominente, conservándose el nuevo Imperio libre del Brasil también independiente. Sobre este particular, puede profundizarse en: Francisco García calderón: Las Democracias Latinas de América. Biblioteca Ayacucho, Caracas, 1979. pp. 29-33.

7 Recuérdese que en ningún caso de Latinoamérica, salvo raros intentos infructuosos de grupos muy focalizados, los sectores populares pudieron salvar, ni aún se inmiscuyeron, en las querellas generadas entre las élites criollas, ni antes ni después de la Independencia; sino que casi siempre, como se explica en el siguiente epígrafe, la tendencia estaba dada en que fueran arrastradas, casi siempre inconscientemente desde el punto de vista político pero no en lo que respecta a la solución que creen óptima para su situación vital, por aquellas como carne de cañón para sus pugnas internas, siendo el ejemplo más típico la Guerra Federal venezolana, entre 1859 y 1863. 
los casos, la lucha por el poder, en medio del objetivo común por usurparlo a las metrópolis, se verá mucho más concentrado entre los elementos regionales, generacionales y aún particulares dentro del sector criollo dirigente que en sus extensiones a otros sectores, pues, allí donde se da esta extensión (como en el caso de Nueva España), los sectores medios y las masas populares no pasan de constituir el consabido instrumento del sector criollo para sus exclusiva toma del poder político, sin posibilidad objetiva ni factual de triunfo concreto para las verdaderas fuerzas motrices del proceso. Por todo esto, si un elemento en común presenta el caso de la Independencia latinoamericana, que lo particulariza en su contexto histórico es precisamente el hecho de que las Guerras de Emancipación sean, a la vez y durante todo el tiempo en que se producen sus sucesos violentos y aún pacíficos, verdaderas Revoluciones Burguesas para no pocos autores. El criterio en torno al carácter mediocre de estas revoluciones por parte de la mayoría de aquellos que aceptan esta convergencia, se ve notablemente injustificado en el hecho de que no es la Revolución Burguesa Moderna un proceso que, incluso en Europa o Estados Unidos, ocurra en forma óptima o mediocre, sino que su riqueza histórica y los particularismos que establece sobre un contexto determinado se hallan en la naturaleza de las transformaciones que tienen lugar producto de ella.

En Latinoamérica, con los logros y limitaciones que puedan notarse, puede determinarse sin lugar a dudas y como elemento indiscutiblemente común la convergencia citada, aunque esta no sea propiamente exclusiva de las Revoluciones Burguesas, y, allí donde el desarrollo de los acontecimientos evite que pueda hablarse de las mismas, tampoco los resultados son otros que una expulsión efectiva de las metrópolis, (pese al neocolonialismo posterior) que incluso fracasarán en toda tentativa posterior de reconquista. De cualquier forma, los grupos desposeídos cambian el dominio extranjero, desde el poder oficial, por un dominio local también desde el poder oficial, igualmente elitista. Si antes tenían dos problemas, ahora tendrán uno de naturaleza doblemente nociva, pues se trata de la explotación del latinoamericano por el latinoamericano. ${ }^{8}$

8 Esta idea, analizada agudamente por José Martí, ha generado en autores como Sergio Guerra Villaboy, entre otros, un insistente discurso en torno a la necesidad impostergable de buscar la Segunda Independencia Latinoamericana. 
El mito de los diferentes caminos políticos emprendidos a partir de tipologías y particularismos en la naturaleza del proceso emancipador, aparece como un fantasma que, lejos de contribuir a la visión más profunda de la Historia de la región, intenta diferenciarla en una medida nociva a los factores reales que pueden potenciar hoy una integración desde orígenes comunes y desarrollos no tan diferentes. En cualquier caso, iniciados con un carácter o naturaleza más o menos radical, las luchas emancipatorias que tuvieron lugar en la región terminaron estableciendo gobiernos elitistas locales.

Si se toma como ejemplo el caso de Río La Plata, pueden encontrarse, durante la Revolución de Mayo, grupos bien definidos como los conciliadores (generales españoles nativos, mayoritariamente partidarios de un gobierno local en forma de cabildo ejercido por ellos) y los patriotas (partidarios de un gobierno propio en forma de cabildo, pero nombrado masivamente, sustituyendo al virrey), que a su vez se dividen en dos corrientes: la que planteaba un gobierno elegido en el propio cabildo (defendida por Cornelio Saavedra), y la que defiende un gobierno nombrado por el pueblo (representada por Castelli, Belgrano, Paso, Moreno y otros). Conjuntamente, se perfilaba la lucha notable entre unitarios (defensores de la hegemonía bonaerense) y federales (que defendían los derechos de las provincias).

Aunque aquí alcancen un mayor impacto que en otras regiones, no puede decirse de la convergencia espacial y temporal de la contradicción entre liberales y conservadores con la lucha entre centralismo y federalismo represente un caso exclusivo, sino más bien generalizado, que durante la Independencia representa un obstáculo para la proclamación de medidas tan radicales como la propia proclamación de ella y la abolición de la esclavitud, y que luego matizará notablemente el vilipendiar político de los Nuevos Estados entre las dictaduras fratricidas y los gobiernos constitucionales notoriamente débiles, ambos incapaces de resolver los conflictos económicos y sociales.

Igualmente, al observar el Proceso Independentista en Nueva España, donde a primera instancia todo indica la existencia de elementos muy típicos que vaticinan 
Novos Estudos Jurídicos

una evolución diferente, puede hallarse, efectivamente, que en sus comienzos el movimiento independentista tuvo un marcado carácter popular, insurreccional y revolucionario. Después del fracaso de la intentona de los ricos mexicanos para constituir una Junta de Gobierno, la principal oposición a España vino de las capas más humildes de la sociedad: los trabajadores indígenas, bajo la dirección política y militar de un ente llamativo: dos sacerdotes humildes. Sin embargo, el carácter profundamente popular con que se inicia la Independencia mexicana debe enfrentar a uno de los reductos más reaccionarios de toda Hispanoamérica: los ricos hacendados y propietarios de minas, quienes, habiendo perdido toda iniciativa y temiendo a la revolución radical, se incorporaron contra el movimiento desde el inicio, y solo conciben el enfrentamiento a España si son ellos quienes lo controlan y promueven desde posiciones marcadamente conservadoras.

Los revolucionarios mejicanos planteaban un Plan de Devastación que señalaba, entre otros elementos, la liquidación del poder económico de los grandes propietarios, la expropiación de los bienes de estos elementos y de la institución católica, así como su reparto inmediato entre los indígenas y la caja del ejército popular; además de la emancipación total de México como principal objetivo de la lucha. Por ello, el caudillo criollo, en este caso Iturbide, utilizará las fuerzas de la desesperada monarquía ibérica para derrotarlos y luego la traicionará, erigiéndose en una tercera alternativa que en realidad siempre ha sido la primera: el poder conservador de los oligarcas criollos, que toman para sí el "mérito" de constituirse como sacrosantos defensores del catolicismo en una de las regiones donde, hasta hoy, éste ha estado más arraigado a los sectores populares; usurpando la iniciativa de los líderes verdaderamente humildes que iniciaron el proceso y aprovechándose de su censura por parte del propio clero español, al cual representan y protegen ahora.

Otros casos no son menos llamativos en cuanto a los destinos nacionales que traerá el proceso liberador. Así, Paraguay se separó de Buenos Aires y creo su propia Junta en Mayo de 1811; La Banda Oriental y su prócer Artigas también lo hicieron, aunque aprovechando mejor el apoyo capitalino para derrotar a los realistas; El Alto Perú hubo de esperar primero por San Martín y luego por Sucre y Bolívar para librar las batallas definitivas en la segunda etapa independentista; 


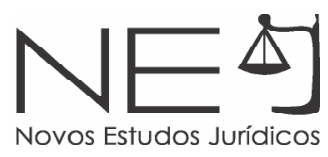

Chile no estuvo seguro hasta la batalla final de Maipú; Brasil requirió que el príncipe regente se convirtiera en abanderado de la causa criolla, etc. Como se observa, los rasgos son disímiles. Sin embargo, en cada una de estas regiones se proclamó la independencia, se logró por vías más o menos violentas y se emprendieron medidas acordes al establecimiento de repúblicas soberanas, sin que las metrópolis pudieran recuperar el espacio perdido.

En todo esto, obviamente, los factores externos, y especialmente los transcurridos en la propia Iberia durante el período en que se produce el proceso liberador, jugarían un papel esencial. Así, Las Cortes de Cádiz y la Constitución Liberal de 1812 -en el caso de Hispanoamérica- dieron paso al restablecimiento de la autoridad española en la mayoría de las regiones peninsulares y a lo que parecía ser un regreso a la normalidad, pues muchos esperaban un nuevo régimen en España que conllevara otra organización política, social y económica de los territorios coloniales. Sin embargo, la reacción absolutista de 1814, producida por el retorno al trono de Fernando VII reanudó las confrontaciones y la guerra abierta. El éxito del pronunciamiento liberal de Rafael del Riego en Cabezas de San Juan (1820) impidió el embarque de las tropas españolas destinadas a América, y con ello facilitó a los patriotas la realización de las últimas campañas militares.

Como se observa, la triple pugna en medio de la Revolución se hace notar con prontitud cuando el sector acaudalado criollo enfrenta, más que a la inicial reacción monárquica, al intento local de radicalización. Ello puede comprobarse, con similares resultados, en lo que plantea Rafael Balde Urzáiz sobre el Proceso Independentista en Venezuela y Nueva Granada, cuando afirma: "De este modo, la necesidad de poder político de los criollos y la difícil situación de las masas trabajadoras (negros esclavos y peones mestizos, principalmente), doblemente explotadas, se convierte en problema de primer orden. El deseo de posesión de la tierra y la libertad personal van potenciando, con la ayuda de las ideas progresistas que penetran, el ideal de la Independencia. Comienzan a cobras auge las ideas de líderes precursores que van apareciendo (...) Se va creando una situación revolucionaria en las juntas de gobierno (...). Durante la primera parte de la lucha (La Patria 
Novos Estudos Jurídicos

Boba) resalta la falta de unidad entre los patriotas neogranadinos (básicamente por razones económicas) y muy enfáticamente entre las diferentes regiones, lo que conduce a una guerra civil entre dos tendencias predominantes: centralistas y federalistas. Este enfrentamiento facilitó la reacción realista y la recuperación por ésta de los territorios rebeldes. En el caso venezolano, se llegan a crear la Primera y Segunda Repúblicas, en las cuales sobresalen las figuras de Miranda y Bolívar (...) Se manifiesta nuevamente la falta de unidad entre los terratenientes criollos regionales y las masas populares (...). Todo dependería luego del mérito bolivariano y de la madurez que son capaces de alcanzar las fuerzas revolucionarias, en buena medida concentradas a partir de las medidas radicales y el genio militar y político del Libertador; cuyo resultado a mediano plazo no es otro que la frustración ante los celos e intrigas que logran quitarle a él y a su pueblo la Revolución para ponerla en manos de los oportunistas criollos".

Además de la contradicción señalada, la cita anterior es de vital importancia al esclarecer otros aspectos no menos trascendentes, $y$, entre ellos, muy particularmente la necesidad de una lucha en común por parte de los grupos sociales latinoamericanos que, si bien sostienen demandas específicas, enfrentan el obstáculo igualmente nocivo del orden colonial, el cual atenta directamente tanto contra su vitalidad y existencia actual como contra la garantía de toda mejora o progreso al respecto. Permite, además, observar cómo las ideas que penetran, pese a las diferencias socioeconómicas, impactan positivamente en la forja del patriotismo como sentimiento común que aúna voluntades y esfuerzos contra la reacción realista, la cual reconquistará espacios solo temporalmente allí donde afloren las conocidas contradicciones regionales y socio-clasistas. Esta reacción terminará siendo nuevamente derrotada por la unidad que, no con poco sacrificio, se conformará en torno a los pilares fundamentales de la necesidad individual objetivamente concreta, que se identifica a su vez con la situación de el otro en el seno de las fuerzas independentistas; y el sentimiento anticolonialista común, con sus ideales emanados; así como la convergencia igualmente en ascenso- de de la necesidad de aplicación de la lucha violenta y radical en el aspecto militar. No obstante, quizás lo más trascendente de este

$9 \quad$ Bladé Urzáiz, Rafael (2000): La Revolución de Independencia en el Norte Sudamericano. Alianza, Madrid, p. 102. 


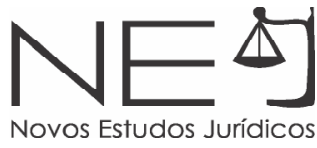

planteamiento está en la idea de que la unidad referida y la búsqueda de la justicia, independientemente de su condicionamiento y desarrollo concreto, pueden ser aceleradas (y de hecho salvadas) por el proceso de maduración política del líder, como puede observarse aquí en el caso de Bolívar y, luego, de manera más clara, en el de José Martí durante la preparación y consumación en la Guerra Necesaria de Cuba (1895-1898), sin excluir a otras importantes figuras.

Bajo ningún concepto puede tampoco admitirse la idea de que existen en América Latina zonas que no se incorporan ni participan directamente del Proceso Emancipador. Lo que sucede, principalmente en el caso de Centroamérica (que, por su dependencia del proceso en Nueva España, sufrió en algún momento de tales aseveraciones) es que los paradigmas independentistas dependen de núcleos ideológicos más visibles y violentos, pero ello no significa que carezcan de participación.

Al respecto de le región centroamericana, debe tomarse en cuenta que, mientras Hidalgo era ejecutado en Chihuahua en 1811, en Nicaragua tenían lugar los primeros brotes independentistas (León, Masaya, Granada y Rivas), con un marcado carácter popular y una alta participación indígena. En 1821, el suceso liberal de la metrópoli estimulaba cambios en toda Centroamérica, mientras que Panamá entraba a formar parte del proyecto bolivariano de La Gran Colombia con el nombre de Departamento del Istmo. Más tarde, cuando el virrey de Nueva España firmaba el Tratado de Córdoba (reconociendo así el Plan de Iguala), la clase criolla de Guatemala, imitando a la de México, firmó el Acta de Independencia. Inmediatamente, justo cuando podían comenzar las pugnas internas, Guatemala recibió la invitación Iturbide para incorporarse al Imperio mexicano, lo cual sucedió en 1822, convirtiéndose este territorio en parte del Imperio, al igual que Nicaragua y Costa Rica, mientras que en los ayuntamientos de San Salvador, San Vicente y Tegucigalpa los liberales, dirigidos por Morazán, rechazaban la idea. En 1823, con la caída de Iturbide y la creación de la República de México, apareció para los liberales el clima propicio, aunque ello no acabara con las contradicciones entre los dos bandos políticos, ni con la lucha entre ciudades que hasta el momento habían llevado la hegemonía regional y otras 
de enorme pujanza, como es el caso de San José y Cartago en Costa Rica (cuya rivalidad desembocó en la Batalla del Alto Ochomogo, que provocó el traslado de la capital a la segunda).

De esta forma, y muy por encima de cualquier otro rasgo, en todos los casos, la potencialidad física de los sectores que habitualmente la empleaban para el trabajo, ahora ha tomado las armas que servirán de instrumento a las consabidas élites ${ }^{10}$, y aún será manipulada también por el poder colonial para hacerle resistencia; en todos los casos -a los efectos de los oportunistas poderososcomo carne de cañón para el enfrentamiento, de la misma manera que luego volverá a su trabajo físico ajeno a la producción para sí en toda la medida en que sus ansias de libertad política lo convocan para la lucha. Los grandes grupos que forman estas fuerzas motrices encontrarán su grueso en el componente étnico y cultural en general que se enfrentó al Invasor durante la conquista, ahora arengado por el producto étnico-cultural de la interacción de ambos.

Sin embargo, pese a lo anterior, la Independencia jurídica se logra en toda la América Latina continental, de una u otra forma. En relación con ella, pero también con sus limitaciones ${ }^{11}$, se concreta un pensamiento integracionista que, en relación directa con las ideas de la Independencia, vendrá ahora a completar un marco único, donde el paradigma de justicia constituye el elemento nuclear. Ello, por supuesto, no puede ser solamente el producto de la Independencia y sus rasgos en sí, sino también del pensamiento de los grandes hombres que la gestan, lo cual requiere de un tratamiento inobjetable.

10 Kossok plantea que "el caudillismo es, por lo tanto, un resultado de la contradicción vida con el carácter incompleto de la revolución entre la súper estructura político-institucional y la base social económica, lo cual es cierto caso de poder altamente generar elementos de una guerra social". Ver en: Manfred Kossok: La Revolución en la Historia de América Latina. Ciencias Sociales. La Habana. 1989, p. 141.

11 Rafael Rojas en Repúblicas de aire, concibe la culminación del primer republicanismo latinoamericano con un sentido pesimista y expone su desarrollo como una deriva hacia el despotismo. Su argumentación es sólida, pero tal situación no indica para nada que había desaparecido el ideario por la justicia social, más bien por el contrario el nuevo republicanismo traía otros problemas que derivaron en la aparición de otras resistencias, que a su vez se orientaron por la búsqueda de la justicia social. Ver: Rojas, Rafael: Repúblicas de aire. Utopía y desencanto en la revolución hispanoamericana. Taurus, España, 2009. 


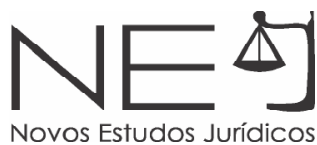

\section{LA JUSTICIA COMO VALOR PARA LOS PROCESOS EMANCIPATORIOS DEL GÉNERO HUMANO}

Sin dudas, el pensamiento político del movimiento emancipador americano -enmarcado históricamente entre los años 1790 y 1825- está condicionado internamente en su surgimiento por una diversidad de situaciones locales imposibles de reconducir por los cánones seguidos en procesos similares ocurridos en Europa y que imponen al desarrollo histórico una impronta peculiar. No menos importante resulta apuntar el contexto internacional en que florece: la crisis más intensa del sistema colonial que obliga a Europa a buscar soluciones ante una inminente transformación y que se reproduce en el pensamiento político de la época.

La evolución lógica del pensamiento político emancipador en las colonias se caracteriza -entonces- por la presencia de corrientes de ideas poco estructuradas con un arraigo desmedido a situaciones locales que sirven de orientador a las minorías dirigentes, a los nuevos sectores populares en la determinación de los objetivos de la acción y en la toma de decisiones políticas. A pesar de sus imprecisiones conceptuales, ofrecieron respuestas a las nuevas situaciones y en esa medida se convirtieron en un escollo infranqueable para el pensamiento político contemporáneo procedente de Europa o de Estados Unidos.

Estas corrientes de ideas tan influyentes que dominaron la práctica en la toma de decisiones políticas no llegaron jamás a formar parte del discurso político, ni de los documentos nacidos al calor del movimiento emancipador (entiéndase constituciones, legislaciones). En tales documentos o discursos figuraron y se enseñorearon los modelos ideológicos europeo y de Estados Unidos. Por eso, en cuanto se trata el pensamiento político jurídico de la emancipación puede decirse sin temor a la equivocación que se adoptaron con fe ciega los modelos y conceptos políticos procedentes de Estados Unidos y Francia, lo que provocó una crisis de eficacia legal, (es decir, carecen de efecto en la práctica social los proyectos legales emancipadores), que, en efecto, es consecuencia de la contradicción modelo extranjero vs situación local avivada 
en todo momento por la existencia de otros puntos de vista internos que ofrecían otras respuestas a los problemas locales; en ese sentido actuaron los caudillos regionales cuyo pensamiento influyó haciéndose realidad social con urgencia en sus zonas de influencia.

Las nuevas respuestas estaban fundamentadas en ideas nacidas del mundo colonial, mestizadas, transculturadas, es el predominio de lo genuinamente americano, acultural, de lo real maravilloso. Son ideas que -evidentementellegaron de Europa, de Estados Unidos, pero que conceptualmente se transformaron y comenzaron a significar otras cosas, para desde ese instante, convertirse en algo distinto a su modelo e imposible de reducir a él. En este contexto socio histórico y político se forja el pensamiento emancipador americano alrededor de la idea de justicia.

Afirmar que la justicia es relativa nos colocaría en una posición filosófica que pareciera indefendible en el contexto de nuestro análisis, por el contrario, la discusión sobre el concepto de justicia pareciera obedecer a la falta de claridad que se deriva de las diferentes aristas del concepto.

Desde los más remotos orígenes del pensamiento griego advertimos que la noción de justicia sufre una visible evolución, que va desde la apreciación de justicia en el mundo familiar gentilicio, hasta la consideración la justicia política, en la sociedad dotada ya de Estado y de la que Aristóteles ${ }^{12}$ es un teórico reconocido. Después de las primeras leyes escritas las nociones de justicia se transformaron, pero en general se siguió entendiendo que el derecho y la justicia derivaban del orden natural. De especial interés resulta la introducción del termino dikayosine ${ }^{13}$ para designar un tipo de justicia "más democrático"14 $L a$ dikayosine encierra la creencia de que en la ley escrita se encuentra el criterio infalible de lo justo y lo injusto y por tanto en la obediencia a las leyes del Estado,

12 La justicia política es para Aristóteles el tercer requisito esencial que debe mantener el cuerpo ciudadano actuando deliberativamente para que exista una polis merecedora de tal denominación y que le permita alcanzar la realización de su finalidad ( Ver la Ética a Nicómano, Libro V, cap. 6, Ética Eudemia, Libro IV, cap. 6)

13 Este vocablo se usa en la antigüedad griega para aludir a la justicia que emana de las leyes escritas.

14 En opinión de Ortiz Rivas "La Dikasoyosine" simboliza la lucha del pueblo heleno contra los gobiernos de minorías que imponen la justicia a su arbitrio; significa la virtud jurídico-política conforme a la cual el individuo libre acepta y obedece la ley escrita como criterio infalible de la justicia y el derecho", Hernán A. Ortiz Rivas: La especulación iusfilosófica en la Grecia Antigua, pág. 59 
lo justo se hace palpable. En los sofistas, especialmente en Calicles ${ }^{15}$ aparece una fuerte polémica acerca del criterio de lo justo, de la cual participa Platón, quien caracteriza al Estado como un todo: "sabio, valiente, moderado y justo"16, y aquí resulta interesante destacar la opinión de Llambías de Azevedo cuando afirma: "Para determinar la esencia de la justicia Platón emplea aparentemente el método de los residuos investigando primero los otros valores, lo que reste será el que buscamos. Pero en realidad se trata de un pretexto para poder exponer también esos valores y establecer sus relaciones con aquella." ${ }^{17}$ Platón se dedica a reflexionar sobre otros valores usando a los mismos como hilo conductor para llegar a la definición de lo justo ${ }^{18}$ La Justicia en su Estado ideal consiste en que cada individuo haga lo que le corresponda según la clase a la que le pertenece, debe ocuparse de lo suyo y no interferir en lo de los otros. La justicia así entendida no pertenece a ninguna clase en particular y se erige como conservadora de las virtudes de esas clases.

Si nos remitimos a Aristóteles vamos a encontrar que el mismo se acerca a la noción de justicia desde diferentes dimensiones: como sinónimo de lo legal (justicia política) define a la justicia como algo universal, ser justo equivale a obedecer la ley y todo ciudadano está en la obligación de cumplir con las leyes del Estado, para ser considerado justo. El Estado aparece entonces como la sede de la virtud por excelencia, es decir, de la justicia como sinónimo de lo equitativo (justicia particular) Aristóteles divide la justicia en: Distributiva, aquella mediante la cual se intenta repartir los bienes de una comunidad de un modo proporcional. Piensa que en tal distribución deberían tenerse en cuenta los méritos de cada uno. Correctiva que se subdivide en justicia que se ocupa de las transacciones

15 Calicles distingue entre lo justo por convención (o 'por ley', nómo), esto es, la igualdad y la fealdad de cometer injusticia, y lo justo por naturaleza (physei), la dominación del fuerte sobre el débil. La ley es sólo la red que los débiles arrojan sobre el león para impedirle moverse. Si la felicidad consiste en el placer, sostiene Calicles, y el placer es la satisfacción de los instintos, el fuerte tiene que ampliar sus instintos lo más posible y tiene derecho a satisfacerlos, y esto sería la justicia. Lo natural y lo justo no es pues una igualdad o hermandad, sino el derecho del más fuerte.

16 Platón, La República, Madrid, Editorial. Aguilar, 1959, pág. 214

17 Llambias de Azebedo, El pensamiento del derecho y el estado en la antigüedad, pág. 278

18 " el justo no quiere aventajar al justo( su semejante) sino al injusto( su contrario). En cambio, el injusto quiere aventajar al justo y al injusto, a su contrario y a su semejante, a todos. Se dice que el injusto se parece al bueno e inteligente, y es como aquel a quien se parece; el justo, lo contrario; por su parte, el malo e ignorante, a su contrario y a su semejante.... Luego el justo se parece al bueno y sabio, el injusto, al malo e ignorante. Y como cada uno es como aquel a quien se parece, el justo será bueno y sabio, el injusto, malo e ignorante" Platón, "La República" en Diálogos, pág. 83 
voluntarias (derecho civil) y la justicia que se ocupa de las involuntarias o forzosas (derecho penal) y por último, la justicia de reciprocidad o conmutativa referida a los tratos llevados a cabo en el ámbito comercial y económico.

La idea de Justicia en Santo Tomas es idéntica la formulada por Ulpiano y retomada después por San Agustín en la Ciudad del Sol:" justicia es la perpetua y constante voluntad de dar a cada uno aquello a que tiene derecho"19

Sin embargo, resulta sorprendente su idea de soberanía ${ }^{20}$ que propugna inscripta, en el pensamiento constitucional burgués. En la Constitución francesa de 1793, que nunca entro en vigor se puede leer: el uso injusto del poder por parte del príncipe o los gobernantes justifica y exige la resistencia activa, incluso la resistencia armada. Para muchos autores en la restauración monárquica se 1868 que se fundamentó en el aspecto jurídico, en el Bill of Right, demostrando la superioridad del Parlamento, están las bases de los principios constitucionales que más tarde nutrieron al movimiento revolucionario burgués, tanto en las colonias británicas de Norteamérica, cuanto en la Francia del siglo XVIII.

La visión política de Locke va a estar influenciada por estos sucesos. Su noción de la tripartición de poderes que desarrolla posteriormente Montesquieu y sus postulados acerca de la soberanía han marcado un hito en el pensamiento jurídico. Para Locke la soberanía reside en el pueblo ${ }^{21}$, el cual posee el derecho de oponerse y sustituir al monarca cuando el mismo no cumpla con el poder que se le ha delegado. En su opinión el pueblo puede escoger la forma de gobierno que considere más adecuada y cambiarla cuando lo estime necesario. ${ }^{22}$

El siglo XVII se encamino a explicar la naturaleza del derecho; además de justificar algún orden político concreto, en especial el despotismo ilustrado. En el afán de asegurar su libertad los hombres se asocian para garantizar sus derechos inalienables e imprescriptibles organizando con ese fin la sociedad civil y el orden político. Algunos como Hobbes transfieren la soberanía de forma total

19 Aquino Tomas. Summa Teológica, cuestión 58

20 Tomas de Aquino considera que la soberanía es patrimonio del pueblo, pero como este es difuso, ignorante y poco orgánico, es justo que se delegue o transfiera al príncipe. La única justificación del poder del príncipe es el ejercicio del bien común. ( Ver: Summa Teológica, cuestión 97)

21 Su concepto de pueblo es restringido. Por pueblo entiende solo a los ciudadanos activos: contribuyentes, propietarios, que son los que gozan de derechos electorales y políticos. Ellos son los únicos depositarios de la soberanía popular.

22 Ver: John Locke Segundo Tratado sobre el Gobierno Civil 
ilimitada e irrevocable en el príncipe, sin reconocer forma posible de oposición En este sentido la justicia pasa a ser el mantenimiento del cumplimiento del acuerdo que da paso a la vida política entre los hombres y debe considerarse injusto cualquier acto que atente contra este convenio ${ }^{23}$. Otros como Spinoza consideran que el hombre no puede enajenar su libertad de modo absoluto en beneficio del gobernante. El convenio solo tiene sentido si la enajenación de la libertad no implica esclavitud y por el contrario conduce a la libertad de todos ${ }^{24}$ Teniendo como fundamento la teoría de origen lockiano sobre la tripartición de poderes, como base de un poder estatal moderado, equilibrado, donde no pueda haber lugar para el autocratismo y el despotismo; en el cual cada uno de los brazos principales de ese poder se contraponga al otro o los otros y de estas contradicciones surge el aludido equilibrio, que deviene una suerte de vigilancia interna del Estado. Otro principio de repercusión indiscutible en la práctica y el pensamiento posterior es el de la supremacía constitucional, donde queda establecida la necesaria subordinación de los estados libres a una norma superior, norma constitucional, que no solo legitima el poder estatal sino que también salvaguarda los derechos ciudadanos.

El pensamiento de Montesquieu aparece muchas veces mezclado con el de Rousseau, como si se tratara de una posición doctrinal única, a pesar de que ambos asumen posiciones diametralmente opuestas en cuanto al ejercicio de la democracia. Lobrano ${ }^{25}$ en su análisis del constitucionalismo moderno caracteriza el poder legislativo propuesto por Rousseau como: tutelado frente a posibles abusos por parte del gobierno, por el tribunado. ${ }^{26}$ Rousseau no admite la democracia representativa porque la democracia y soberanía, que son consustanciales al pueblo, no pueden enajenarse ni cederse. De tal forma, la llamada democracia representativa, en cuanto supone enajenación de la soberanía, deja de ser democracia y por ende poder del pueblo ${ }^{27}$.

23 Tomas Hobbes: Leviatán, Primera Parte

24 ".....los derechos de la naturaleza, que son absolutos y que en lo que al hombre respecta no tiene otro valladar o limite que el de su propio poder, se ceden por indicación de la razón, en personal beneficio de los cedentes y para su mejor garantía por parte de la sociedad" Benito Spinoza Tratado teológico- político, cap. III pág. 47

25 Ver: Giovanni Lobrano. Modelo romano y constitucionalismos modernos, Universidad de Externado de Colombia, Bogotá, 1990.

26 Según Rousseau " ne pouvant rien faire il peut tout empêcher " ( si bien no puede hacer nada, puede impedirlo todo)

27 "el pueblo inglés se cree libre, pero está en grave error; es libre únicamente durante la elección de los miembros del parlamento; tan pronto como pasa la elección, es esclavo, nada es" Juan J Rousseau El Contrato social, en Obras Escogidas, Ed. Ciencias políticas, Instituto Cubano del Libro, la Habana, 1973pág. 29 
Es el momento para hacer dos precisiones. Idea -en términos filosóficosdesigna el sentido, la significación, la esencia. El ideal -por su parte- es una representación sobre el orden social más perfecto en consonancia con los intereses económicos y políticos de un grupo social. En consecuencia, la idea de justicia social o el ideal de justicia social, identifican el orden social más perfecto con aquel que tenga por esencia la justicia.

No obstante, se ha dicho que un ideal no es una fórmula muerta, sino una hipótesis perfectible, para que sirva debe ser concebida así, actuante en función de la vida social que incesantemente deviene. Todo ideal representa un nuevo estado de equilibrio entre el pasado y el porvenir ${ }^{28}$. El ideal de justicia social -entonces - para europeos o norteamericanos era corregido por los pensadores de las colonias emancipadas buscando y adoptando un nuevo estado de equilibrio para el futuro, un nuevo contenido. Lo justo es un concepto ético, una valoración moral de un fenómeno social, es un concepto histórico. De manera corriente se habla de equidad como equivalente a justicia, pero de modo preferente para significar la solución justa de un caso determinado. Una solución equitativa es la que parece adecuada o correcta en unas circunstancias determinadas, como algo que corresponde a la justicia natural.

Ciertamente se ha dicho que es más fácil reconocer una injusticia que definir la justicia; en razón de ello, puede decirse -igualmente- que es más fácil tener el convencimiento de que una solución es equitativa que tener el acierto de definir la equidad, sin embargo los intentos en este sentido florecen por doquier en la doctrina más moderna ${ }^{29}$.

En el concepto de justicia, dice Coing $^{30}$, existe una antinomia. Es la contradicción entre la exigencia de igualdad y la de justicia individual. El carácter general de las normas permite tratar igual a casos iguales; pero este mismo carácter general puede tener un inconveniente para llegar a una solución justa en

28 Ingenieros, José; El hombre mediocre, editorial Ciencias Sociales, 2001, pág. 8.

29 En tal sentido los trabajos importantísimos del especialista Ralph Newman, entre sus publicaciones: Equity and law: A comparative study, New York, Ocean Publication, 1961; The role of equity in the harmonization of legal systems, Washintog College of Law, The American University, 1963; además la obra colectiva dedicada a René Cassin y dirigida por el mismo Newman Equity in te world's legal systems, Bruselas, Etablissements Emile Bruylant, 1973.

30 Coing, H. Fundamentos de la filosofía del Derecho, Barcelona, ediciones Ariel, 1961, pág. 128. 
casos determinados. Si la justicia reclama igualdad, también exige que sea tratado cada caso con sus propias circunstancias, sus propiedades, sus particularidades, y ha de procurarse que el carácter general de las normas no obligue a desconocer circunstancias de las que puede depender que la solución sea justa. De esa manera aparece el concepto clásico de equidad como la justicia del caso particular.

De todas formas, los cuestionamientos no terminan aquí. Hay que preguntarse qué significa la justicia del caso individual más allá de sus fronteras. La solución equitativa obliga a preguntar por qué ha sido justa la solución lograda a costa de apartarse de algún modo de la norma general.

La norma general no puede ser censurada por la existencia de un caso excepcional, pero la solución equitativa también puede haber sido necesaria por la circunstancia de que las normas generales ya no estén debidamente ajustadas a las necesidades actuales. Así la equidad adquiere -entonces- otro sentido, porque puede anunciar un Derecho nuevo, mejor ${ }^{31}$ que el proclamado por la normativa vigente. Si este es el caso, la equidad contiene aquí una reflexión sobre la misión del Derecho, es su conciencia.

En síntesis, pudieran identificarse dos funciones principales de la equidad: por una parte proporciona principios básicos para la interpretación de las leyes y de las declaraciones de voluntad en cualquier negocio jurídico; y por otra, como conciencia del Derecho, se convierte en impulsora de la renovación legal, impulsora de la búsqueda del enlace entre el Derecho actual y el del futuro.

La idea de equidad es muy antigua. Aparece formulada en Aristóteles como corrección de las leyes que por su mismo carácter general no pueden ajustarse a todas las circunstancias de los casos en que han de aplicarse. Epieikeia en griego y aequitas en latín son las palabras empleadas para significar la solución que mitiga la rigidez de la norma general. El Derecho ha de ser completado por la equidad, la regla general por la excepción, para que siempre pueda alcanzarse una solución humana. Por estar formuladas las normas en términos generales, la equidad ha de estar dispuesta a intervenir para que la justicia se logre en cada

31 El concepto de mejor es un resultado natural de la evolución misma. Es resultado del perfeccionamiento constante. 
caso individual ${ }^{32}$. Se encuentra pacíficamente aceptado el criterio de diferencia entre las actitudes griegas y romanas ante el tema de la justicia. Los griegos no dudaban en desviarse de las normas generales para dar soluciones ajustadas a los hechos de cada caso particular. Por ello, Grecia no ha transmitido a la posteridad un sistema de jurisprudencia, a diferencia de lo que aportó en los otros grandes temas del arte, la política y la filosofía. Por el contrario, el genio de Roma se manifestó al lograr que las soluciones prácticas cristalizaran en formas jurídicas susceptibles de formar un sistema ${ }^{33}$. Los griegos decidieron que era preferible dar soluciones prácticas y justas a sus contemporáneos que trasmitir reglas venerables a la posteridad y la discusión aristotélica sobre la equitativa interpretación de la leyes ha influido no solo en los juristas romanos, sino a través de Santo Tomás, en todo el mundo occidental. He ahí los más importantes aportes griegos al Derecho.

Otro desarrollo es el de la equity inglesa. Es una equidad administrada por una jurisdicción independiente, el Tribunal de la Cancillería, que se definió como un derecho separado, paralelo al derecho común. La equidad inglesa comenzó como una manera de dispensar la justicia sin más fundamento que la razón natural, pero terminó por ser una jurisdicción que aplicaba un cuerpo normativo perfectamente estructurado, que hacía innecesaria la apelación a la conciencia y al Derecho natural. Luego se fusionaron las jurisdicciones en un mismo tribunal a partir de 1875, pero ya la equity estaba tan enraizada como conjunto normativo que se sigue estudiando por separado y produciendo una serie de efectos peculiares, aún emanando de los mismos Tribunales.

El devenir de la equity inglesa es un ejemplo de la diferencia entre equidad entendida como solución de justicia natural para cada caso y un sistema de Derecho nacido para perfeccionar o complementar a otro ya existente, pero que termina por necesitar otros impulsos de la justicia natural. Es así, que cuando las soluciones de equidad han quedado integradas en el Derecho positivo ${ }^{34}$, sigue persistiendo la idea de equidad, es decir, sigue siendo indispensable aplicar el Derecho según los

32 Huntington, Cairns. Legal philosophy from Plato to Hegel, Baltimore, The John Hopkins Press, 1949, page 107110.

33 Sobre estos temas ver: H.S. Maine en Ancient law, Madrid, Editorial La España Moderna, 1861; y Jerome Frank en Courts on Trial, Princeton University Press, 1949.

34 Sobre el tema ver los trabajos de Vicente Torralba en Derecho Civil, volumen 1, Barcelona, 1953. 
dictámenes de la razón natura| ${ }^{35}$. Cuando se encierra el término equidad en una fórmula legal, la equidad misma se domestica, se convierte en conservadora.

Desde la segunda mitad del siglo pasado y fundamentalmente de desde la publicación de la principal obra de John Rawls ${ }^{36}$, la justicia se asoció a equidad y comenzó a indistinguirse de la primera en el plano conceptual, a lo cual contribuyó en cierta medida la traducción de la obra rawlsiana ${ }^{37}$, pero la crítica fundamental a esta teoría se asocia a que la teoría de Rawls es una "disculpa" del status quo, en tanto construye su idea de justicia desde la práctica existente y excluye la posibilidad de que puedan darse problemas de justicia inherentes a las relaciones sociales capitalistas, a la propiedad privada, o a la economía de mercado $^{38}$.

\section{CONCLUSIONES}

\section{La idea de justicia se conforma de acuerdo a las experiencias concretas y}

35 Las llamadas máximas de la equidad inglesa que resumen los criterios básicos de la actuación del Tribunal de la Cancillería son las siguientes:

La equidad no permite que un agravio quede sin remedio.

La equidad sigue a la ley.

Primero en tiempo, primero en derecho.

Cuando las equidades estén equilibradas el Derecho prevalecerá.

Quien pide equidad ha de estar dispuesto a hacer equidad.

Quien acude a la equidad ha de tener las manos limpias.

Vigilantes, no dormidos, la equidad va a venir.

Igualdad es equidad.

La equidad mira la intención más que a la forma.

La equidad considera como hecho lo que se está obligado a hacer.

La equidad imputa al obligado la voluntad de cumplir la obligación.

La equidad actúa in personam.

36 Ver: Rawls, J. Teoría de la justicia. FCE, México 2006.

37 Dentro de los principales problemas de esta traducción es que no se corresponde ni a la edición de 1971 ni a la de 1993, sino a un manuscrito que Rawls tenía para la traducción alemana de 1975. En lo que corresponde al contenido, se encuentran varios problemas como por ejemplo el uso indiscriminado de right como derecho, sin tener a la vista el contexto de la discusión filosófica en la cual muchas veces right ha de entender como "lo recto" o "lo correcto", como por ejemplo en la tensión "the good and the right".

38 Aquí el crítico principal es Robert P. Wolf. Ver: Paterson, R.W. K. Authority, Autonomy and the Legitimate State. Journal of Applied Philosophy, Vol. 9, No. 1, 1992 
Novos Estudos Jurídicos

clasistas de sus promotores, de ahí que como se ha dicho, haya podido de servir de disculpa a la conservación del status quo e integrada en el Derecho positivo, pero dicha concepción de justicia no se corresponde con la evolución que esta idea tendrá en el proceso independentista latinoamericano.

\section{BIBLIOGRAFÍA}

Aquino, Tomás de. Summa Teológica. Traducción, presentación y anotación de Julio Picasso Muñoz. Lima, Perú: Fondo Editorial de la Universidad Católica Sedes Sapientiae, 2008.

Aristóteles. Ética a Nicómano, Libro V, cap. 6, Traducción y Notas de José Luis Calvo Martínez, Alianza Editorial, Madrid, 2001.

Ética Eudemia, Libro IV, cap. 6, traducción y notas de J. Pallí Bonet, Gredos, Madrid 1985.

Coing, H. Fundamentos de la filosofía del Derecho, Barcelona, ediciones Ariel, 1961.

Frank, Jerome. Courts on Trial. Princeton University Press, 1949.

Hobbes, Tomás. Leviatán, o La materia, forma y poder de una república eclesiástica y civil. Fondo de Cultura Económica, México, 2008.

Huntington, Cairns. Legal philosophy from Plato to Hegel.Baltimore, The John Hopkins Press, 1949.

Kossok, Manfred. La Revolución en la Historia de América Latina. La Habana, Ciencias Sociales, 1989.

Lobrano, Giovanni. Modelo romano y constitucionalismos modernos, Universidad de Externado de Colombia, Bogotá, 1990.

Locke, John. Segundo Tratado sobre el Gobierno Civil: un ensayo acerca del verdadero origen, alcance y fin del gobierno civil, trad. de Carlos Mellizo, Clásicos del pensamiento, Madrid, Tecnos, 2006.

Maine, H. S. Ancient Law.Madrid, Editorial La España Moderna, 1861.

Newman, Ralph. Equity and law: A comparative study, New York, Oceana Publication, 1961.

.The role of equity in the harmonization of legal systems, Washington College of Law-The American University, 1963.

. Equity in the world's legal systems, Brussels, Establishments Emile Bruylant, 1973.

Paterson, R.W. K. "Authority, Autonomy and the Legitimate State". Journal of Applied Philosophy, Vol. 9, No. 1, 1992 
Platón.La República, Madrid, Editorial. Aguilar, 1959.

Rawls, John. Teoría de la justicia. Fondo de Cultura económica, México, 2006.

Rojas, Rafael: Repúblicas de aire. Utopía y desencanto en la revolución hispanoamericana. Taurus, España, 2009.

Rousseau, Juan J. El Contrato social, En: Obras Escogidas, Ed. Ciencias políticas, Instituto Cubano del Libro, La Habana, 1973.

Spínoza, Baruch. Tratado teológico-político, Madrid: Alianza, 2003

Torralba, Vicente. Derecho Civil, volumen 1, Barcelona, 1953.

Weber, Max. La Ética Protestante y el Espíritu del Capitalismo. Ediciones Península, Barcelona, 1994.

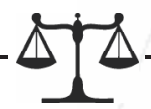

